\title{
Strategy-proof location of a public bad on a disc
}

Citation for published version (APA):

Öztürk, M., Peters, H. J. M., \& Storcken, A. J. A. (2012). Strategy-proof location of a public bad on a disc. METEOR, Maastricht University School of Business and Economics. METEOR Research Memorandum No. 041 https://doi.org/10.26481/umamet.2012041

Document status and date:

Published: 01/01/2012

DOI:

10.26481/umamet.2012041

Document Version:

Publisher's PDF, also known as Version of record

\section{Please check the document version of this publication:}

- A submitted manuscript is the version of the article upon submission and before peer-review. There can be important differences between the submitted version and the official published version of record.

People interested in the research are advised to contact the author for the final version of the publication, or visit the DOI to the publisher's website.

- The final author version and the galley proof are versions of the publication after peer review.

- The final published version features the final layout of the paper including the volume, issue and page numbers.

Link to publication

\footnotetext{
General rights rights.

- You may freely distribute the URL identifying the publication in the public portal. please follow below link for the End User Agreement:

www.umlib.nl/taverne-license

Take down policy

If you believe that this document breaches copyright please contact us at:

repository@maastrichtuniversity.nl

providing details and we will investigate your claim.
}

Copyright and moral rights for the publications made accessible in the public portal are retained by the authors and/or other copyright owners and it is a condition of accessing publications that users recognise and abide by the legal requirements associated with these

- Users may download and print one copy of any publication from the public portal for the purpose of private study or research.

- You may not further distribute the material or use it for any profit-making activity or commercial gain

If the publication is distributed under the terms of Article $25 \mathrm{fa}$ of the Dutch Copyright Act, indicated by the "Taverne" license above, 


\section{Maastricht University}

Murat Öztürk, Hans Peters, Ton Storcken

Strategy-proof location of a public bad on a disc

RM/ 12/041

\section{METEOR}

Maastricht University School of Business and Economics

Maastricht Research School of Economics

of Technology and Organization

P.O. Box 616

NL - 6200 MD Maastricht

The Netherlands 


\title{
Strategy-proof location of a public bad on a disc
}

\author{
Murat Öztürk* Hans Peters* Ton Storcken*
}

July, 2012

\begin{abstract}
In a model with finitely many agents who have single-dipped Euclidean preferences on a disc in the Euclidean plane, a rule assigns to each profile of reported dips a point of the disc. It is proved that any strategy-proof and Pareto optimal rule is a dictatorial. This framework models situations where public bads such as garbage dumping grounds or nuclear plants have to be located within a confined region that has the shape of a disc.
\end{abstract}

JEL Classification: D71

Keywords: Single-dipped preferences, strategy-proofness

\section{$1 \quad$ Introduction and model}

This paper contributes to the following question: Where to locate a public bad (noxious facility) like for instance a garbage dumping ground or nuclear plant within a given region? Specifically, we assume that a finite number of agents, equipped with single-dipped Euclidean preferences, reaches a decision by voting. The dips (worst locations) of these agents are private knowledge e.g., residence, children's school, etc. - and thus we require the (voting) rule to be strategy-proof in order to elicit the true information about these dips. We also require the rule to be Pareto optimal, and assume the region to be a disc, i.e., a circle and its interior, in the Euclidean plane. This choice is quite specific. In a companion paper (Öztürk et al, 2012) we study strategy-proof and Pareto optimal rules for the case where $A$ is a polytope in $\mathbb{R}^{2}$, i.e., the convex hull of finitely many points. We find that such rules can be based on majority voting and more generally voting by committees (simple games) if either the region is sufficiently flat (in terms of width) or the region is (basically) a rectangle and its inside. In all other cases such rules are dictatorial, including all regular polytopes except for the square. We conjecture that similar results will hold on general compact convex sets, being the 'limits' of polytopes, and in the present note indeed show dictatorship on the disc. We need, however, a separate proof

*Maastricht University, Department of Quantitative Economics, P.O. Box 616, 6200 MD Maastricht, The Netherlands. Email addresses: M.Ozturk@maastrichtuniversity.nl, H.Peters@maastrichtuniversity.nl, T.Storcken@maastrichtuniversity.nl. 
and are not (yet) able to extend the result for polytopes by some limit argument. The general case of compact convex regions in $\mathbb{R}^{2}$ is therefore still open.

Formally, we consider the following collective decision problem. The set of alternatives is the $\operatorname{disc} A=\left\{x \in \mathbb{R}^{2}:\|x\| \leq 1\right\}$, where $\|\cdot\|$ denotes Euclidean distance. The set of agents is $N=\{1, \ldots, n\}$ with $n \geq 2$. Each agent has a single-dipped Euclidean preference on $A$, characterized by a dip $a \in A$ such that $x \in A$ is weakly preferred to $y \in A$ if and only if $\|x-a\| \geq\|y-a\|$. A profile is a vector $p \in A^{N}$, where $p(i)$ is the dip of agent $i$, for each $i \in N$. A rule $\varphi$ assigns to each $p \in A^{N}$ a collective decision $\varphi(p) \in A$. A rule $\varphi$ is strategyproof if for all $i \in N$ and $p, q \in A^{N}$ with $p(j)=q(j)$ for all $j \in N \backslash\{i\}$ we have $\|\varphi(p)-p(i)\| \geq\|\varphi(q)-p(i)\|$. It is not difficult to verify that strategy-proofness is equivalent to the following property, which we will use interchangeably. A rule $\varphi$ is intermediate strategy-proof if for every coalition $S \subseteq N$ and all profiles $p, q \in A^{N}$ such that $p(j)=q(j)$ for all $j \in N \backslash S$ and there is an alternative $a$ with $p(i)=a$ for all $i \in S$, we have $\|\varphi(p)-a\| \geq\|\varphi(q)-a\|$. A rule $\varphi$ is Pareto optimal if for every $p \in A^{N}$, every $a \in A$ and every $i \in N$, if $\|a-p(i)\|>\|\varphi(p)-p(i)\|$ then there is a $j \in N$ such that $\|a-p(j)\|<\|\varphi(p)-p(j)\|$.

Other existing work on strategy-proofness under single-dipped preferences (for the public good/bad case) is confined to one-dimensional regions, specifically Peremans and Storcken (1999), Barberà et al (2009), and Manjunath (2009). In our proof below we use decisive coalitions and ultrafilters, cf. Hansson (1976). There is also a literature on locating noxious facilities if monetary transfers are possible, see e.g. Kunreuther and Kleindorfer (1986) for a relatively early reference.

\section{Dictatorship}

In this section we prove our main result.

Theorem 2.1 Let $\varphi: A^{N} \rightarrow A$ be a rule. Then $\varphi$ is strategy-proof and Pareto optimal if and only if $\varphi$ is dictatorial, i.e., there is an agent $d$ such that $\| \varphi(p)-$ $p(d)\|\geq\| x-p(d) \|$ for every $p \in A^{N}$ and every $x \in A$.

Observe that for every $x \in A \backslash\{0\}$ (where $0=(0,0) \in \mathbb{R}^{2}$ ) there is a unique point on the boundary $\partial A$ of $A$ that has maximal distance from $x$; we denote this point by $\widehat{x}$. In particular, if $x \in \partial A$ then $\widehat{x}=-x$. If $x=0$ then all points of $\partial A$ are at maximal distance (namely, 1) from $x$. Hence, if $\varphi$ is dictatorial with dictator $d$ then $\varphi(p)=\widehat{p(d)}$ whenever $p(d) \neq 0$, and $\varphi(p) \in \partial A$ if $p(d)=0$.

For $a, b \in \partial A$ we denote the closed arc between $a$ and $b$ by $[a \curvearrowleft b]$. (If $b=-a$ then $[a \frown b]$ is defined to be $\partial A$, i.e., the full circle.) Also, $[a \frown b[=[a \frown b] \backslash\{b\}$, ]$a \frown b]=[a \frown b] \backslash\{a\}$, and $] a \frown b[=[a \frown b] \backslash\{a, b\}$.

For $x, y \in A$ and $S \subseteq N$ we denote by $p=\left(x^{S}, y^{N \backslash S}\right)$ the profile with $p(i)=x$ for all $i \in S$ and $p(i)=y$ for all $i \in N \backslash S$. The first lemma says that if $\varphi$ is Pareto optimal then it assigns a boundary point to each such two-dip profile. 
Lemma 2.2 Let $\varphi: A^{N} \rightarrow A$ be Pareto optimal, and let $x, y \in A$ and $S \subseteq N$. Then $\varphi\left(x^{S}, y^{N \backslash S}\right) \in \partial A$.

Proof. Let $a=\varphi\left(x^{S}, y^{N \backslash S}\right)$. If $a \notin \partial A$ then let $\ell$ be the straight line through $a$ and perpendicular to the straight line $\ell^{\prime}$ through $x$ and $y$ if $x \neq y$; if $x=y$ then let $\ell$ be the straight line through $a$ and $x$. The line $\ell$ intersects $\partial A$ in a point $b$ on the other side of $a$ than the point of intersection with $\ell^{\prime}$, or the point $x$ if $x=y$. Then $b$ Pareto dominates $a$ at the profile $\left(x^{S}, y^{N \backslash S}\right)$, a contradiction.

Until further notice, $\varphi: A^{N} \rightarrow A$ is strategy-proof and Pareto optimal.

Lemma 2.3 Let $a \in \partial A$ and $S \subseteq N$. Then $\varphi\left(a^{S}, \widehat{a}^{N \backslash S}\right) \in\{a, \widehat{a}\}$.

Proof. In the proof only two-dip profiles are considered: therefore, by Lemma 2.2 , their outcomes under $\varphi$ are in $\partial A$. Contrary to what is to prove, assume that $\varphi\left(a^{S}, \widehat{a}^{N \backslash S}\right)=b$ where $b \notin\{a, \widehat{a}\}$. Without loss of generality we may assume that $\|a-b\| \leq\|\widehat{a}-b\|$. For $x, y \in \partial A$ let $y_{x}$ be the point on $\partial A$ such that $\left\{y, y_{x}\right\}=\{z \in \partial A:\|x-z\|=\|x-y\|\}$.

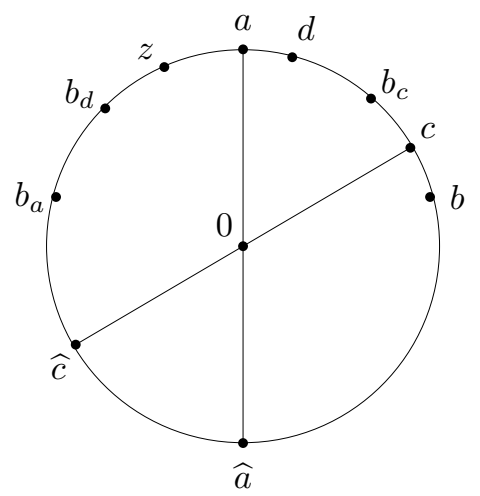

(a)

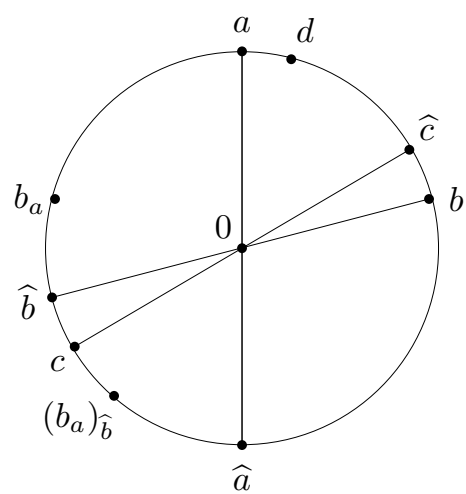

(b)

Figure 1: Illustrating the proof of Lemma 2.3; $z=\varphi\left(c^{S}, \widehat{a}^{N \backslash S}\right)$

First we prove that $\varphi\left(b^{S}, \widehat{a}^{N \backslash S}\right)=b_{a}$. (See Fig. 1(a).) Consider $c \in[a \frown b[$. Since $\|a-b\| \leq\|\widehat{a}-b\|$, strategy-proofness implies $\varphi\left(c^{S}, \widehat{a}^{N \backslash S}\right) \in\{b\} \cup\left[b_{c} \frown b_{a}\right]$. Pareto optimality yields that $\varphi\left(c^{S}, \widehat{a}^{N \backslash S}\right) \in[\widehat{c} \frown a]$. Clearly $b \notin[\widehat{c} \frown a]$. So, $\varphi\left(c^{S}, \widehat{a}^{N \backslash S}\right) \in\left[b_{c} \frown b_{a}\right]$. Note that we just showed that $\varphi\left(x^{S}, \widehat{a}^{N \backslash S}\right) \in\left[b_{x} \frown b_{a}\right]$ for all $x \in\left[a \frown b\left[\right.\right.$. Suppose $\varphi\left(c^{S}, \widehat{a}^{N \backslash S}\right) \neq b_{a}$. Then we can choose $d \in[a \frown c[$ such that $\left.\left.\left[b_{d} \frown b_{a}\right] \subseteq\right] \varphi\left(c^{S}, \widehat{a}^{N \backslash S}\right), b_{a}\right]$. Since $\varphi\left(d^{S}, \widehat{a}^{N \backslash S}\right) \in\left[b_{d} \frown b_{a}\right]$ this implies that $\left\|\varphi\left(d^{S}, \widehat{a}^{N \backslash S}\right)-c\right\|>\left\|\varphi\left(c^{S}, \widehat{a}^{N \backslash S}\right)-c\right\|$, which obviously contradicts strategyproofness. So, $\varphi\left(c^{S}, \widehat{a}^{N \backslash S}\right)=b_{a}$. Since the choice of $c$ was arbitrary this proves that $\varphi\left(x^{S}, \widehat{a}^{N \backslash S}\right)=b_{a}$ for all $x \in[a \frown b[$. Strategy-proofness now implies that $\varphi\left(b^{S}, \widehat{a}^{N \backslash S}\right)=b_{a}$.

Next we prove (see Fig. 1(b)) that $\varphi\left(b^{S}, \widehat{b}^{N \backslash S}\right) \in\left\{b_{a},\left(b_{a}\right)_{\hat{b}}\right\}$. Consider $c \in$ $\widehat{] b} \frown \widehat{a}\left[\right.$. Since $\varphi\left(b^{S}, \widehat{a}^{N \backslash S}\right)=b_{a}$, strategy-proofness implies that $\varphi\left(b^{S}, c^{N \backslash S}\right) \in$ 
$\left\{b_{a}\right\} \cup\left[\left(b_{a}\right)_{c} \frown b\right]$. Since Pareto optimality implies $\varphi\left(b^{S}, c^{N \backslash S}\right) \subseteq[\widehat{b} \frown \widehat{c}]$ it follows that $\varphi\left(b^{S}, c^{N \backslash S}\right)=b_{a}$. So we proved that $\varphi\left(b^{S}, x^{N \backslash S}\right)=b_{a}$ for all $\left.x \in\right] \widehat{b} \frown \widehat{a}[$. Strategy-proofness now implies that $\varphi\left(b^{S}, \widehat{b}^{N \backslash S}\right) \in\left\{b_{a},\left(b_{a}\right)_{\hat{b}}\right\}$.

Finally we prove $\varphi\left(b^{S}, \widehat{b}^{N \backslash S}\right)=b$, which is a contradiction since $b \notin$ $\left\{b_{a},\left(b_{a}\right)_{\hat{b}}\right\}$, and thus completes the proof. Since $\varphi\left(a^{S}, \widehat{a}^{N \backslash S}\right)=b$, strategyproofness implies $\varphi\left(a^{S}, \widehat{b}^{N \backslash S}\right)=b$. For $d \in[a \frown b[$ strategy-proofness implies $\varphi\left(d^{S}, \widehat{b}^{N \backslash S}\right) \in\{b\} \cup\left[b_{d} \frown b_{a}\right]$. Pareto optimality now implies that $\varphi\left(d^{S}, \widehat{b}^{N \backslash S}\right)=b$. By the arbitrary choice of $d$ we have $\varphi\left(x^{S}, \widehat{b}^{N \backslash S}\right)=b$ for all $x \in[a \frown b[$. So strategy-proofness implies $\varphi\left(b^{S}, \widehat{b}^{N \backslash S}\right)=b$.

The next lemma shows that at two-dip profiles as in Lemma 2.3 always the same coalition gets its best point.

Lemma 2.4 Let $S \subseteq N$. Then either $\varphi\left(x^{S}, \widehat{x}^{N \backslash S}\right)=\widehat{x}$ for all $x \in \partial A$ or $\varphi\left(x^{S}, \widehat{x}^{N \backslash S}\right)=x$ for all $x \in \partial A$.

Proof. Let $a, b \in \partial A$. In view of Lemma 2.3 we may assume without loss of generality that $\varphi\left(a^{S}, \widehat{a}^{N \backslash S}\right)=\widehat{a}$. It is sufficient to prove that $\varphi\left(b^{S}, \widehat{b}^{N \backslash S}\right)=\widehat{b}$. We distinguish two cases.

Case 1: $\{a, \widehat{a}\} \cap\{b, \widehat{b}\}=\emptyset$. To the contrary, suppose $\varphi\left(b^{S}, \widehat{b}^{N \backslash S}\right) \neq \widehat{b}$. Then Lemma 2.3 yields $\varphi\left(b^{S}, \widehat{b}^{N \backslash S}\right)=b$. Strategy-proofness and $\varphi\left(a^{S}, \widehat{a}^{N \backslash S}\right)=\widehat{a}$ imply $\varphi\left(a^{S}, \widehat{b}^{N \backslash S}\right)=\widehat{a}$. But strategy-proofness and $\varphi\left(b^{S}, \widehat{b}^{N \backslash S}\right)=b$ imply $\varphi\left(a^{S}, \widehat{b}^{N \backslash S}\right)=b$. This yields the contradiction $b=\widehat{a}$.

Case 2: $b=\widehat{a}$. So, $\{a, \widehat{a}\}=\{b, \widehat{b}\}$. Take $c \in \partial A \backslash\{a, \widehat{a}, b, \widehat{b}\}$. Applying the previous case yields first $\varphi\left(c^{S}, \widehat{c}^{N \backslash S}\right)=\widehat{c}$ and by this result that $\varphi\left(b^{S}, \widehat{b}^{N \backslash S}\right)=$ $\widehat{b}$.

Call a coalition $S \subseteq N$ decisive if for every $a \in A$ and every profile $p \in A^{N}$ with $p(i)=a$ for all $i \in N$ we have $\varphi(p)=\widehat{a}$ if $a \neq 0$ and $\varphi(p) \in \partial A$ if $a=0$. The next two lemmas deal with decisive coalitions.

Lemma 2.5 Let $S \subseteq N$. Then $S$ is decisive or $N \backslash S$ is decisive.

Proof. In view of Lemma 2.4, we may assume without loss of generality that $\varphi\left(a^{S}, \widehat{a}^{N \backslash S}\right)=\widehat{a}$ for all $a \in \partial A$. We prove that $S$ is decisive. Take $b \in A$ and $p \in A^{N}$ such that $p(i)=b$ for all $i \in S$. It is sufficient to prove that $\varphi(p)$ is at maximal distance from $b$. We distinguish two cases.

Case $1: \quad b \neq 0$. Let $c=-\widehat{b}$. By assumption $\varphi\left(c^{S}, \widehat{b}^{N \backslash S}\right)=\widehat{b}$. But then strategy-proofness implies $\left\|b-\varphi\left(b^{S}, \widehat{b}^{N \backslash S}\right)\right\| \geq\|b-\widehat{b}\|$. Hence, $\varphi\left(b^{S}, \widehat{b}^{N \backslash S}\right)=\widehat{b}$. Strategy-proofness now implies $\varphi(p)=\widehat{b}$.

Case 2: $b=0$. By the previous case it follows that $\varphi(q) \in \partial A$ for all profiles $q$ such that $q(j)=p(j)$ for all $j \in N \backslash S$ and $q(i)=x$ for all $i \in S$, for some $x \in A \backslash\{0\}$. Now strategy-proofness implies that $\varphi(p) \in \partial A$.

Lemma 2.6 Let $S, T \subseteq N$ be both decisive. Then $S \cap T$ is decisive. 
Proof. To the contrary suppose that $S \cap T$ is not decisive. Then, by Lemma 2.5, $N \backslash(S \cap T)$ is decisive. Let $X=S \backslash T, Y=S \cap T$, and $Z=N \backslash S$. So $X \cup Y=S, Y \cup Z=N \backslash(S \backslash T) \supseteq T$ and $X \cup Z=N \backslash(S \cap T)$ are decisive. Further, let $p=\left(a^{X}, b^{Y}, c^{Z}\right)$ with $a, b, c \in \partial A$ (hence agents in $X$ have their dips at $a$, agents in $Y$ at $b$, and agents in $Z$ at $c$ ), and such that $a, b$, and $c$ are the vertices of an equilateral triangle. (See Fig. 2(a).) Since $X \cup Y$ is decisive,

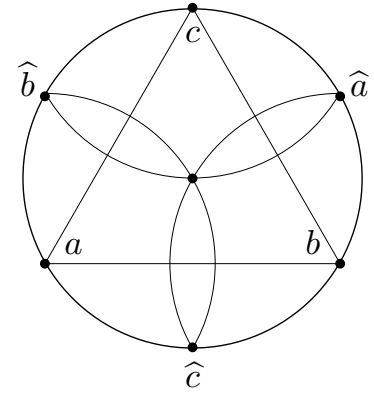

(a)

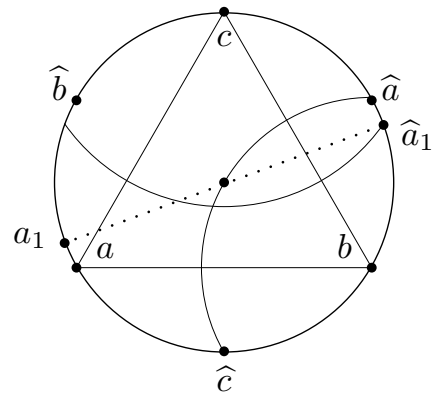

(b)

Figure 2: Illustrating the proof of Lemma 2.6

hence $\varphi\left(b^{X \cup Y}, c^{Z}\right)=\widehat{b}$, it follows by strategy-proofness that

$$
\|a-\varphi(p)\| \geq\|a-\widehat{b}\| .
$$

Similarly, since $X \cup Z$ and $Y \cup Z$ are decisive we have $\varphi\left(a^{X \cup Z}, b^{Y}\right)=\widehat{a}$ and $\varphi\left(a^{X}, c^{Y \cup Z}\right)=\widehat{c}$ so that strategy-proofness implies that

$$
\|c-\varphi(p)\| \geq\|c-\widehat{a}\| \text { and }\|b-\varphi(p)\| \geq\|b-\widehat{c}\| .
$$

Therefore, $\varphi(p) \in\{0, \widehat{a}, \widehat{b}, \widehat{c}\}$, but 0 is Pareto dominated by for instance $\widehat{a}$. Without loss of generality, assume that $\varphi(p)=\widehat{a}$. Take $\left.a_{1} \in\right] a \frown \widehat{b}[$ close to $a$. By applying the above argument with $a_{1}$ instead of $a$, we find for the profile $p^{\prime}=\left(a_{1}^{X}, b^{Y}, c^{Z}\right)$ in particular the inequalities $\left\|c-\varphi\left(p^{\prime}\right)\right\| \geq\left\|c-\widehat{a}_{1}\right\|$ and $\left\|b-\varphi\left(p^{\prime}\right)\right\| \geq\|b-\widehat{c}\|$. For points $x \in A$ satisfying these inequalities we have (see Fig. 2(b)) $\left\|a_{1}-x\right\| \leq\left\|a_{1}-\widehat{c}\right\|$, hence in particular $\left\|a_{1}-\varphi\left(p^{\prime}\right)\right\| \leq\left\|a_{1}-\widehat{c}\right\|$. Since $\left\|a_{1}-\widehat{c}\right\|<\left\|a_{1}-\widehat{a}\right\|$ by the choice of $a_{1}$, and since $\varphi(p)=\widehat{a}$, coalition $X$ can manipulate from $p^{\prime}$ to $p$, and thus we have a violation of strategy-proofness.

By Pareto optimality and Lemmas 2.5 and 2.6 the collection $\mathcal{D}$ of decisive coalitions satisfies (i) $\emptyset \notin \mathcal{D}$, (ii) if $S, T \in \mathcal{D}$, then $S \cap T \in \mathcal{D}$, and (iii) $S \in \mathcal{D}$ or $N \backslash S \in \mathcal{D}$. Thus, $\mathcal{D}$ is an ultrafilter and it is well-known and straightforward to prove that there is a unique $d \in N$ with $\{d\} \in \mathcal{D}$. Clearly then, $\varphi$ is dictatorial with dictator $d$. This proves the only-if direction of Theorem 2.1. Since, trivially, a dictatorial rule is strategy-proof and Pareto optimal, the proof of Theorem 2.1 is complete. 


\section{References}

Barbera S, Berga D, Moreno B (2009) Single-dipped preferences. Barcelona Economics Working Paper Series No 418

Hansson B (1976) The existence of group preference functions. Public Choice 38, 89-98

Kunreuther H, Kleindorfer PR (1986). A sealed-bid auction mechanism for siting noxious facilities. American Economic Review (Papers and Proceedings) 76:295299

Manjunath V (2009) Efficient and strategy-proof social choice when preferences are single-dipped. Working paper

Öztürk M, Peters H, Storcken T (2012) On the location of public bads: strategyproofness under two-dimensional single-dipped preferences. Research Memorandum, Maastricht

Peremans W, Storcken T (1999) Strategy-proofness on single-dipped preference domains. In de Swart HMC (ed.) Logic, Game theory and Social choice. Tilburg University Press, The Netherlands 